\title{
O processo do cuidar do bebê prematuro: percepções da mãe adolescente e equipe de enfermagem
}

\author{
The process of caring for premature baby: perceptions of the adolescent mother and \\ nursing team
}

El proceso del cuidar del bebé prematuro: percepciones de la madre adolescente y equipo de enfermería

Marieli Elaine Honório ${ }^{1}$, Ludmilla Laura Miranda ${ }^{1}$, Milena Torres Guilhem Lago ${ }^{1 *}$, Keli Regiane Tomeleri da Fonseca Pinto ${ }^{1}$, Adriana Valongo Zani' .

\section{RESUMO}

Objetivo: Apreender as percepções da mãe adolescente e da equipe de enfermagem face ao cuidado ao filho prematuro hospitalizado na unidade neonatal. Método: Trata-se de uma pesquisa de abordagem qualitativa com Triangulação de dados. Realizado em um hospital escola na região norte do Paraná, Brasil. Ocorrido de janeiro a junho de 2017, dividiu-se em quatro etapas: entrevista com a mãe adolescente, entrevista com os profissionais de enfermagem envolvidos no cuidado, analise do prontuário dos gêmeos e observação dos cuidados prestados. Os dados coletados por entrevistas foram gravados e seguidos de análise de conteúdo temática. Resultados: A análise possibilitou a construção de oito categorias: Gravidez indesejada; Sentindo-se incapaz; Medo e culpa frente o nascimento prematuro; Confiança na equipe; Tornando-se mãe, Dificuldade de trabalhar com mães adolescentes, Imaturidade para ser mãe, Desenvolvendo responsabilidade. Considerações finais: É possível trabalhar com a mãe adolescente permitindo que ela participe efetivamente do cuidado do filho. Cabe à equipe de enfermagem, bem como aos demais profissionais envolver a adolescente o mais precocemente possível nos cuidados ao filho, mesmo que com cuidados simples, de forma que a adolescente possa se familiarizar com o novo membro da família e deste modo fortalecer o vínculo familiar.

Palavras chave: Prematuridade, Adolescência, Enfermagem, Cuidado.

\begin{abstract}
Objective: To understand the perceptions of the adolescent mother and the nursing team regarding the care of the premature child hospitalized in the neonatal unit. Method: This is a qualitative research with Data Triangulation. Held in a school hospital in the northern region of Paraná, Brazil. Between January and June of 2017, it was divided into four stages: interview with the adolescent mother, interview with the nursing professionals involved in the care, analysis of the chart of the twins and observation of the care provided. The data collected by interviews were recorded and followed by thematic content analysis. Results: The analysis allowed the construction of eight categories: Unwanted pregnancy; Feeling incapable; Fear and guilt over premature birth; Trust in the team; Becoming a mother, Difficulty working with teenage mothers, Immaturity to be a mother, Developing responsibility. Final considerations: It is possible to work with the adolescent mother allowing her to participate effectively in the care of the child. It is up to the nursing team as well as other professionals to involve the teenager as early as possible in the care of the child, even with simple care, so that they can become familiar with the new family member and thus strengthen the family bond.
\end{abstract}

Keywords: Prematurity, Adolescence, Nursing, Care.

${ }^{1}$ Universidade Estadual de Londrina (UEL). * E-mail: milena mtg@hotmail.com

SUBMETIDO EM: 11/2018

ACEITO EM: 12/2018

PUBLICADO EM: $\mathbf{3 / 2 0 1 9}$

REAS/EJCH | Vol. 11 (7) | e566 | DOI: https://doi.org/10.25248/reas.e566.2019 Página 1 de 7 


\section{RESUMEN}

Objetivo: Apreciar las percepciones de la madre adolescente y del equipo de enfermería frente al cuidado al hijo prematuro hospitalizado en la unidad neonatal. Método: Se trata de una investigación cualitativa con Triangulación de datos. Realizado en un hospital escuela en la región norte de Paraná, Brasil. En el curso de enero a junio de 2017, se dividió en cuatro etapas: entrevista con la madre adolescente, entrevista con los profesionales de enfermería involucrados en el cuidado, análisis del prontuario de los gemelos y observación de los cuidados prestados. Los datos recogidos por entrevistas fueron grabados y seguidos de análisis de contenido temático. Resultados: El análisis posibilitó la construcción de ocho categorías: Embarazo no deseado; Sintiéndose incapaz; Miedo y culpa frente al nacimiento prematuro; Confianza en el equipo; Se convierte en madre, Dificultad de trabajar con madres adolescentes, Inmunidad para ser madre, Desarrollando responsabilidad. Consideraciones finales: Es posible trabajar con la madre adolescente permitiendo que ella participe efectivamente del cuidado del hijo. Cabe al equipo de enfermería, así como a los demás profesionales involucrar a la adolescente lo más precozmente posible en los cuidados al hijo, aunque con cuidados simples, de forma que puedan familiarizarse con el nuevo miembro de la familia y de este modo fortalecer el vínculo familiar.

Palavras-clave: Prematuridad, Adolescencia, Enfermería, Cuidado.

\section{INTRODUÇÃO}

A definição de adolescência corresponde ao período entre 10 e 19 anos de idade, reconhecidamente uma época de transições físicas, biológicas e psicológicas (WORLD HEALTH ORGANIZATION, 2013).

As mudanças nesse período estão vinculadas ao aprendizado da sociabilidade, dos modelos de gêneros, dos valores, das moralidades sociais e das dificuldades advindas, experiências que ampliam suas vulnerabilidades. O comportamento sexual é uma das expressões do comportamento juvenil que ganhou grande visibilidade e ações de controle social (GONÇALVES, et al 2015).

O início precoce da atividade sexual e, principalmente, de forma desprotegida, tem elevado os índices de gestações não planejadas decorrentes de relacionamento com parceiros igualmente jovens (BRASIL, 2017)

Deste modo a gravidez na adolescência por si só desencadeia um turbilhão de sentimentos, por não ser considerado o melhor momento para a vinda de um filho. E associado a este acontecimento o nascimento de um filho prematuro que emergir na vida familiar de maneira inesperada, é percebida pela família como um ser inacabado, que pode até mesmo ser rejeitado. Essa forma de perceber o prematuro gera insegurança, desencadeando intensas mudanças e transformações na vida de cada um de seus membros; uma condição que pode gerar danos emocionais para toda a família, especialmente para pais adolescentes (ZANI et al, 2014).

Portanto, tornar-se mãe no período da adolescência, somado ao nascimento de um filho prematuro, pode desencadear diversos sentimentos e necessidade de acompanhamento pela equipe de enfermagem e demais profissionais de saúde. Sendo assim, o objetivo deste estudo foi, apreender as percepções da mãe adolescente e da equipe de enfermagem face ao cuidado ao filho prematuro hospitalizado na unidade neonatal.

\section{MÉTODO}

Trata-se de um estudo de abordagem qualitativa que utilizou a Triangulação de dados obtidos mediante diferentes técnicas de coleta: entrevista, observação e análise documental.

O cenário do estudo foi à unidade neonatal de um de um hospital escola localizado na região norte do Paraná. Credenciado pelo Sistema Único de Saúde (SUS), sendo este referência para gestação de alto risco e cuidado ao recém-nascido prematuro.

Participaram deste estudo uma mãe adolescente de bebês gemelares que nasceram prematuros e três residentes de enfermagem que a assistiram essa mãe e seus filhos durante todo o período de internação. 
O estudo realizou-se em quatro etapas, a primeira, entrevista com a mãe adolescente, segundo entrevista com os profissionais de enfermagem envolvidos, terceiro análise do prontuário dos gêmeos e quarto observação dos cuidados prestados.

A princípio foram realizadas as entrevistas separadamente, primeiramente com a mãe adolescente e posteriormente com os profissionais de enfermagem, para tanto foi utilizado um roteiro semi-estruturado. As entrevistas foram gravadas e foi utilizado caderno de campo para síntese do pesquisador. Ao término da entrevista solicitava-se a mãe e aos profissionais de enfermagem que ouvisse a gravação da entrevista e a leitura da síntese realizada, garantindo a ele o direito de alterar as informações, caso julgasse necessário.

A duração média do encontro das pesquisadoras com os participantes foi de 30 minutos, considerando a interação inicial e a entrevista propriamente dita. A coleta de dados ocorreu no período de janeiro a junho de 2017.

Após iniciou-se a observação dos cuidados da mãe aos filhos, bem como da assistência prestada pela equipe de enfermagem que estava assistindo essa mãe. As observações seguiram-se de anotações e análise prévia. Os critérios da observação de campo por informações da realidade contribuíram na identificação e obtenção provas "a respeito de objetivos sobre os quais os indivíduos não têm consciência, mas que orientam seu comportamento" (BARDIN, 2016).

Posteriormente deu-se início a análise do prontuário procurou avaliar a coerência entre a realidade observada e os registros. A entrevista com os profissionais de enfermagem auxiliaram na percepção do cuidado da mãe adolescente com o filho prematuro.

Os dados foram trabalhados por meio da análise de conteúdo que consiste em descobrir os núcleos de sentido que compõem uma comunicação e cuja presença ou frequência de aparição pode significar alguma coisa para o objetivo analítico escolhido.

A pesquisa se deu após a aprovação do Comitê de Ética em Pesquisa da Universidade Estadual de Londrina, CAAE: 30709814.0.0000.5231. Para garantir o anonimato, o nome da equipe de enfermagem foi substituído pela letra $E$ seguida de sequência numérica e em decorrência de ser apenas uma mãe adolescente participante o mesmo foi substituída apenas pela denominação mãe.

\section{RESULTADOS}

A mãe entrevistada possui 16 anos, é solteira, não mantém mais relacionamento com o pai, no momento cursando o primeiro ano do ensino médio, sua gestação teve uma duração de 23 semanas e 5 dias, sendo uma gestação de gemelares, ambos os recém-nascidos do sexo feminino com peso de 580 e 555 gramas. 0 tempo de internação das suas filhas foi de aproximadamente 210 dias, no dia do nascimento das gemelares foi necessário manobras de reanimação, intubação e encaminhamento para a Unidade de Terapia Intensiva neonatal. Em decorrência da prematuridade extrema as gemelares apresentaram inúmeras intercorrências, tais como falha de extubação, distúrbios respiratórios, pneumonia associada à ventilação mecânica, enterocolite, dificuldade de desmame do oxigênio, pausas respiratórias e hemorragia intracraniana.

Os profissionais de enfermagem participantes foram três residentes de enfermagem, do segundo ano da residência, tendo 1 ano e 6 meses de experiência com mães e bebês prematuros. No que tange a faixa etária dos profissionais as mesmas possuem entre 24 a 27 anos, a escolha por estes profissionais foi o fato de terem acompanhado toda a trajetória desta mãe desde o nascimento das gemelares todo o período de internação até o momento da alta.

A análise possibilitou a construção de oito categorias: Gravidez indesejada; Sentindo-se incapaz; Medo e culpa frente o nascimento prematuro; Confiança na equipe; Tornando-se mãe; Dificuldade de trabalhar com mães adolescentes; Imaturidade para ser mãe; Desenvolvendo responsabilidade.

De modo geral, o adolescente ao iniciar sua atividade sexual não se preocupa com as consequências, no entanto ao se deparar com uma gravidez, surgem sentimentos de negação e desejo que está gestação não tenham continuidade como observado no discurso a seguir. 


\section{Gravidez indesejada}

"[...] Eu na verdade nunca quis ficar gravida, eu não sonhava em ter filho, nunca planejei casar e ter filhos, eu planejava em ter uma família formada apenas por mim e meu futuro marido. Quando eu descobri que estava gravida eu não aceitei, eu quis tirar, nossa eu fiz de tudo, ainda cheguei a falar para o pai delas que eu não queria, mas na época eu também não sabia que eram gêmeas." (mãe)

Posterior à materialização da gravidez o adolescente percebe-se incapaz de assumir os cuidados de uma nova vida, bem como começa a se conscientizar das barreiras que surgirão nesta etapa e das mudanças que acarretaram em sua vida.

\section{Sentindo-se incapaz}

"[...] Eu pensava meu Deus, como é que eu vou cuidar de uma criança se eu nem sei cuidar de mim mesma e eu tenho que terminar meus estudos. Eu me sentia incapaz, quando eu descobri que eram gêmeas ainda, eu dizia eu mal sei limpar uma casa, não tem como eu cuidar de duas crianças, e eu e o pai delas não estávamos mais juntos, então como cuidar sozinha das duas, eu me senti totalmente incapaz de cuidar delas." (mãe)

O profissional de enfermagem compartilha desta dificuldade da adolescente sentir-se incapaz de assumir este novo papel, ou de ser mãe como relatado a seguir.

"[...] Então especificamente a gente olha uma mãe adolescente e percebemos que ela não tem muita noção da maternidade, elas demoram um pouco para aderir isso como mãe." (E 2)

No entanto percebe-que a mãe adolescente a partir do momento que aceita a gestação, mas percebe a gravidade do filho, sente-se culpada pela situação e com medo da morte.

\section{Medo e culpa frente o nascimento prematuro}

"[...] Eu estava me sentindo inútil, eu pensava nossa eu não prestei nem pra segurar minhas filhas... Eu fiquei bastante triste. meu pensamento quando eu as vi pela primeira vez, eu falava assim eu engravidei a toa, arrumei o enxoval tudo a toa, para não sobreviver, não adianta eu chegar e me apegar nelas porque eu sei que elas não vão sobreviver, eu me sentia assim, muito triste." (mãe)

No entanto, a confiança na equipe, devido às orientações recebidas gerou confiança e gratidão como observado a seguir.

\section{Confiança na equipe}

"[...] Por conta da idade das meninas e por já estarem bem elas tinham que ir para outra unidade, mas eu não queria quando disseram que não tinham mais como segurar a internação delas na neonatal eu chorei, porque eles me explicavam tudo que iam fazer com as nenéns, qual ia ser o procedimento, o que elas tinham pegado, as infecções me falavam, os antibióticos que eles iam entrar, os PICCs (cateter central de inserção periférica) que eles iam passar, eles me avisavam tudo eu confiava muito neles eram meu apoio." (mãe)

A adolescente percebe os profissionais como fonte de apoio, no entanto a equipe tem claro que trabalhar com uma adolescente que se torna mãe e especificamente de um bebê prematuro, é um grande desafio que gera inúmeras dificuldades.

\section{Dificuldade de trabalhar com mães adolescentes}

"[...] Eu acho que trabalhar com uma mãe adolescente, não sei se pela idade ou pela falta de experiência, ela demanda mais nosso tempo, atenção e paciência da gente." (E 1) 
Outro fato importante percebido pelos profissionais de enfermagem é que a mãe adolescente em decorrência da imaturidade tem dificuldade de compreender o que significa ser mãe e as mudanças que irão repercutir.

\section{Imaturidade para ser mãe}

"[...] Parecem que não tem muito o pensamento de que o filho é delas, que elas têm que cuidar, é como se fossem um brinquedinho." (E 1)

"[...] Pois fazemos isso com todas as mães, não tem algo muito especifico só as orientações que temos que repetir mais vezes, pela imaturidade mesmo." (E 2)

"[...] No começo tem mães que pela inexperiência tem muito medo, elas tremem para realizar o mais simples cuidados ou para tocar seu filho. Mas com o tempo, lógico que nas primeiras vezes são mais difíceis, ela vão perdendo um pouco do medo." (E3)

E diante das adversidades da adolescência, do parto prematuro, da gemelaridade, momentos de felicidade são percebidos quando a adolescente percebe-se mãe.

\section{Tornando-se mãe}

A primeira vez que peguei elas de verdade foi cinco segundos, mas foi os cinco segundos mais felizes da minha vida. Elas eram minhas, e estavam vivas, aí a esperança veio e ficou, neste momento me senti mãe e percebi o quanto já as amava (mãe)

A adolescente ao sentir-se verdadeiramente mãe aos poucos desenvolve a responsabilidade frente 0 cuidado do filho.

\section{Desenvolvendo responsabilidade}

"[...] Mas com o tempo percebo que estas mães adolescentes vão se envolvendo mais, começam a se perceber responsáveis por aquele bebê, passam a tomar consciência da complexidade de se ter um filho prematuro e dos riscos que isto acarreta e aos poucos vão desenvolvendo a maternidade." (E 1)

"[...] Mas em geral, quando se tornam mãe, não são muito responsáveis, porém com o passar do tempo quando cai a ficha de que realmente são mães, a responsabilidade começa a se fazer presente na vida dessa mãe." (E 2)

"[...] No caso especifico desta mãe adolescente, ela é bem jovem, uma gestação precoce, imatura e não tinha a noção do que era ter um filho, ainda mais gêmeos, principalmente prematuros, você falava as coisas para ela tudo era brincadeira, então ela não levava nada a sério. Quando ela foi de alta daqui da unidade, a ficha dela caiu. A gente deu as orientações aqui para ela. A gente fez uma visita no domicilio dela uma semana após a alta para ver como ela estava se saindo e quais dúvidas ela tinha, e ela falou "eu não sei o que eu faço" caiu a ficha que ela tinha duas bebês, e que ela era responsável pelas duas bebês, até então ela não tinha isso em mente." (E3)

\section{DISCUSSÃO}

Os índices de gravidez não desejada infelizmente são muito altos e somados a este fator tem crescido estatisticamente a gravidez na adolescência em decorrência do início cada vez mais precoce da atividade sexual (BRASIL, 2017)

A gravidez na adolescência pode iniciar um processo de conflitos, medos, e até de atitudes precipitadas para interrompê-la. A insegurança de assumir perante a família, do medo de não ser aceita pelos familiares e pelo parceiro, faz com que a gravidez seja um evento não desejado (SANTOS; SANTOS; MOTA et al., 2015). 
A maternidade pode trazer diversas alterações na vida da mulher, exigindo dela uma adaptação às novas funções de cuidados com o recém nascido. Algumas mulheres, por não estarem preparadas emocionalmente para vivenciar a maternidade naquele momento, podem apresentar algumas dificuldades para assumir o papel materno, além de se sentir incapazes de cuidar do bebê (GREINERT; MILANI, 2015).

Normalmente a gravidez não planejada vem sendo uma crise individual vivenciada pela mãe adolescente o que aumenta os riscos inerentes as mesmas como: a morbidade fetal e outros riscos de saúde nesta gestação (VIEIRA; LAUDADE; MONTEIRO et al., 2013).

A adolescente mãe de um bebê nascido prematuro vivencia um período de estresse do qual emergem inúmeros problemas e preocupações, incluindo o medo frente ao momento de fragilidade e risco ao qual o filho está exposto; temem apegar-se ao bebê e este não sobreviver; insegurança quanto aos cuidados; ansiedade em relação à doença, tratamento e recuperação do bebê, entre outros. Isso provoca alterações no cotidiano, abalando vivência e dinâmica familiar (BARROSO; PONTES; ROLIM, 2015).

No momento em que a equipe se disponibiliza a ajudar esta nova mãe e busca formas de comunicação efetiva ocorre o surgimento da confiança e do bom relacionamento entre mãe e equipe (SANTOS; SANTOS; MOTA et al., 2015).

O processo de trabalho do enfermeiro em UTIN, para que este seja cada vez mais dinâmico em relação à qualidade da assistência prestada ao neonato e sua família, no sentido de fornecer apoio, escuta, cuidado humanizado, técnico e ético aos sujeitos envolvidos neste ambiente (SOARES; LIMA; SOARES et al., 2014).

A assistência pré-natal de qualidade é importante na prevenção de riscos associados à gestação e ao período neonatal, tornando-se imprescindível o acompanhamento adequado às gestantes, às parturientes $e$ ao neonato (SANTOS; WILHELM; ALVES et al., 2014).

Reconhece-se que o apoio social da família é essencial para promoção da saúde da mãe adolescente e seu filho, deste modo garantindo o protagonismo da adolescente frente às vivências da maternidade. Visto ser no meio familiar que as mulheres e principalmente as adolescentes buscam apoio e recursos para se capacitarem para o cuidado do filho (VIEIRA; LAUDADE; MONTEIRO et al., 2013).

No entanto, para a equipe atuante na unidade neonatal trabalhar com a mãe adolescente, fazendo-a compreender seu novo papel e ajudá-la a vencer e superar suas dificuldades e imaturidade é visto como um grande desafio, uma vez que demanda maior disponibilidade do profissional (SOARES; LIMA; SOARES et al., 2014).

Tornar-se mãe na adolescência é tido como um fator de risco, visto que a adolescência é um momento de transição do ser humano, e em decorrência deste fato a imaturidade emocional é uma característica marcante sendo este considerado um fator de risco. Pois estas adolescentes possuem a capacidade fisiológica para gerar filhos, no entanto requerem um período de amadurecimento da personalidade frente a maternidade(VIEIRA; LAUDADE; MONTEIRO et al., 2013).

Compreende-se que a maternidade é um período de transformações para a vida adulta, na qual a jovem passa a assumir um papel significativo, de mudanças e readaptações, para estabelecer novos papéis de responsabilidade. Não é apenas uma questão de transformação física, mas também uma transformação relativa à vida social, que deve ser analisada e compreendida, pois implica em novos projetos no cotidiano de vida destas adolescentes (SANTOS; WILHELM; ALVES et al., 2014).

\section{CONSIDERAÇÕES FINAIS}

Considera-se que os objetivos do estudo foram atingidos visto que foi possível apreender as percepções da mãe adolescente e da equipe de enfermagem face ao cuidado ao filho prematuro hospitalizado na unidade neonatal.

Dentre as percepções da mãe em relação ao cuidado do filho prematuro emergiram sentimentos contraditores como não desejo da gravidez, incapacidade de cuidar e após medo e culpa pela situação do 
filho prematuro. Em relação à equipe de enfermagem observou-se que a equipe possui maior dificuldade em trabalhar com a mãe adolescente, em decorrência de sua imaturidade, no entanto percebem que o convívio com o filho na unidade favorece o desenvolvimento do vínculo afetivo e as mesmas passam a se tornar mães e consequentemente passam a se responsabilizar pelo cuidado.

Assim, cabe salientar que é possível trabalhar com a mãe adolescente permitindo que ela participe efetivamente do cuidado do filho. Cabe à equipe de enfermagem, que atua com a mãe adolescente no ambiente hospitalar, envolve-la mais precocemente possível nos cuidados ao filho, de forma que estas mães adolescentes possam se familiarizar com o novo membro da família e deste modo fortalecer o vínculo familiar.

\section{REFERÊNCIAS}

1. AMARAL JB, RESENDE TA, CONTIM D et al. Equipe de enfermagem diante da dor do recém-nascido prétermo. Escola Anna Nery Revista de Enfermagem, Rio de Janeiro, 2014; 18(2): 241-46.

2. BARDIN, L. Análise de conteúdo. São Paulo: Edições; 2016; 70.

3. BARROSO ML, PONTES AL, ROLIM KMC. Consequências da prematuridade no estabelecimento do vínculo afetivo entre mãe adolescente e recém-nascido. Revista Rede de Enfermagem do Nordeste, 2015; 16(2): 168-75.

4. BRASIL. Ministério da Saúde. Secretaria de Atenção à Saúde. Departamento de Ações Programáticas e Estratégicas. Proteger e cuidar da saúde de adolescentes na atenção básica [recurso eletrônico] / Ministério da Saúde, Secretaria de Atenção à Saúde, Departamento de Ações Programáticas e Estratégicas. - Brasília : Ministério da Saúde, 2017. 234 p. : il.

5. GONÇALVES H, MACHADO EC, SOARES ALG et al. Início da vida sexual entre adolescentes (10 a 14 anos) e comportamentos em saúde Sexual. Revista Brasileira de Epidemiologia, 2015; 18: 25-41.

6. GREINERT BRM, MILANI RG. Depressão pós-parto: uma compreensão psicossocial. Psicologia: teoria e prática, vol.17, n.1, p. 26-36, 2015.

7. JAGER ME, DIAS ACG. A Paternidade na Percepção de Adolescentes de Classes Populares. Psicologia: Ciência e Profissão, 2015; 35(3): 694-710.

8. ROBERT KYIN. Estudo De Caso: Planejamento e Métodos, 2015, 5: 2-22.

9. SANTOS NLAC, COSTA MCO, AMARAL MTR et al. Gravidez na adolescência: análise de fatores de risco para baixo peso, prematuridade e cesariana. Ciência \& Saúde Coletiva, 2014; 19(3): 719-726.

10. SANTOS CC, WILHELM LA, ALVES CN et al. A vivência da gravidez na adolescência no âmbito familiar e social. Revista Enfermagem UFSM, 2014; 4(1) 105-112.

11. SANTOS PFBB, SANTOS ADB, MOTA GM et al. Significados da maternidade/paternidade para adolescentes que vivenciam esse processo. Revista de Enfermagem do Centro Oeste Mineiro, 2015; 5 (2): 1629-42.

12. SOARES LG, LIMA VF, SOARES LG et al. Enfermagem neonatal em cuidados intensivos: o olhar das famílias. Revista da Rede de Enfermagem do Nordeste, 2014; 15(1): 12-21.

13. VIEIRA APR, LAUDADE LGR, MONTEIRO JCS et al. Maternidade na adolescência e apoio familiar: implicações no cuidado materno à criança e autocuidado no puerpério. Ciência, Cuidado e Saúde, 2013; 12(4): 679-687.

14. WORLD HEALTH ORGANIZATION (WHO). Health topics. Adolescent health, 2013 [citado em 18 Nov 2017 ]. Disponível em: http://www. who.int/topics/adolescent_health/en/. (Acessado em 18 de novembro de 2017).

15. ZANI AV, TONETE VLP, LIMA CMGP. Maternal representations about the provision of care to newborns at risk: a collective discourse. Online Brazilian Journal of Nursing, 2014; 13(3):321-31. 